\title{
Instrumentos de evaluación
}

\section{Evaluation instruments}

\author{
Eduardo Vázquez-Domínguez ${ }^{a *}$, María del P. Gómez-Ortiz ${ }^{a}$
}

\begin{abstract}
:
Evaluation instruments within the teaching-learning process, the evaluation is a basic element, since it allows to assess the level of performance and achievement of learning, in other words it is a way of collecting, systematizing and analyzing information in order to measure and improve the student learning, and the means to obtain them are the evaluation techniques and instruments; instruments defined as structured resources designed for specific purposes (SEP 2013).
\end{abstract}

Among these Instruments we have the following:

Informal, semi-formal and formal evaluation. The first of them having as its main characteristic observation; the second application in specific exercises or in the collection of products and the last to specific exams.

The relevant and appropriate use of each instrument allows to demonstrate the performance of the students in three specific criteria that are: evidence of knowledge, evidence of performance and evidence of the product which are integrated into a portfolio.

Keywords:

Evaluation, Instrument, performance.

\section{Resumen:}

Dentro del proceso de enseñanza aprendizaje, la evaluación es un elemento básico, dado que permite valorar el nivel de desempeño y logro de los aprendizajes en otras palabras, es una forma de recolección, sistematización y análisis de información con el objetivo de medir y mejorar el aprendizaje de los alumnos, y el medio para su obtención son las técnicas e instrumentos de evaluación, instrumentos definidos como recursos estructurados diseñados para fines específicos (SEP 2013)

Entre estos Instrumentos tenemos las siguientes:

Evaluación informal, semiformal y formal. La primera de ella teniendo como su principal característica la observación; la segunda la aplicación en ejercicios específicos o bien en la recolección de productos y la última a exámenes específicos.

El uso pertinente y adecuado de cada instrumento permite evidenciar el desempeño de los alumnos en tres criterios específicos que son: evidencia de conocimientos, evidencia de desempeño y evidencia del producto las cuales son integradas a un portafolio.

\section{Palabras Clave:}

Evaluación, Instrumento, desempeño.

a Escuela Superior Tepeji del Rio, Programa Bachillerato General, Universidad Autonoma del Estado de Hidalgo, Av Del Maestro No. 41 Col. Noxtongo 2a Seccion, Tepeji del Rio Hidalgo, Mexico, CP.42855 Email:* evd2000@yahoo.com.mx, mapili_30@hotmail.com 


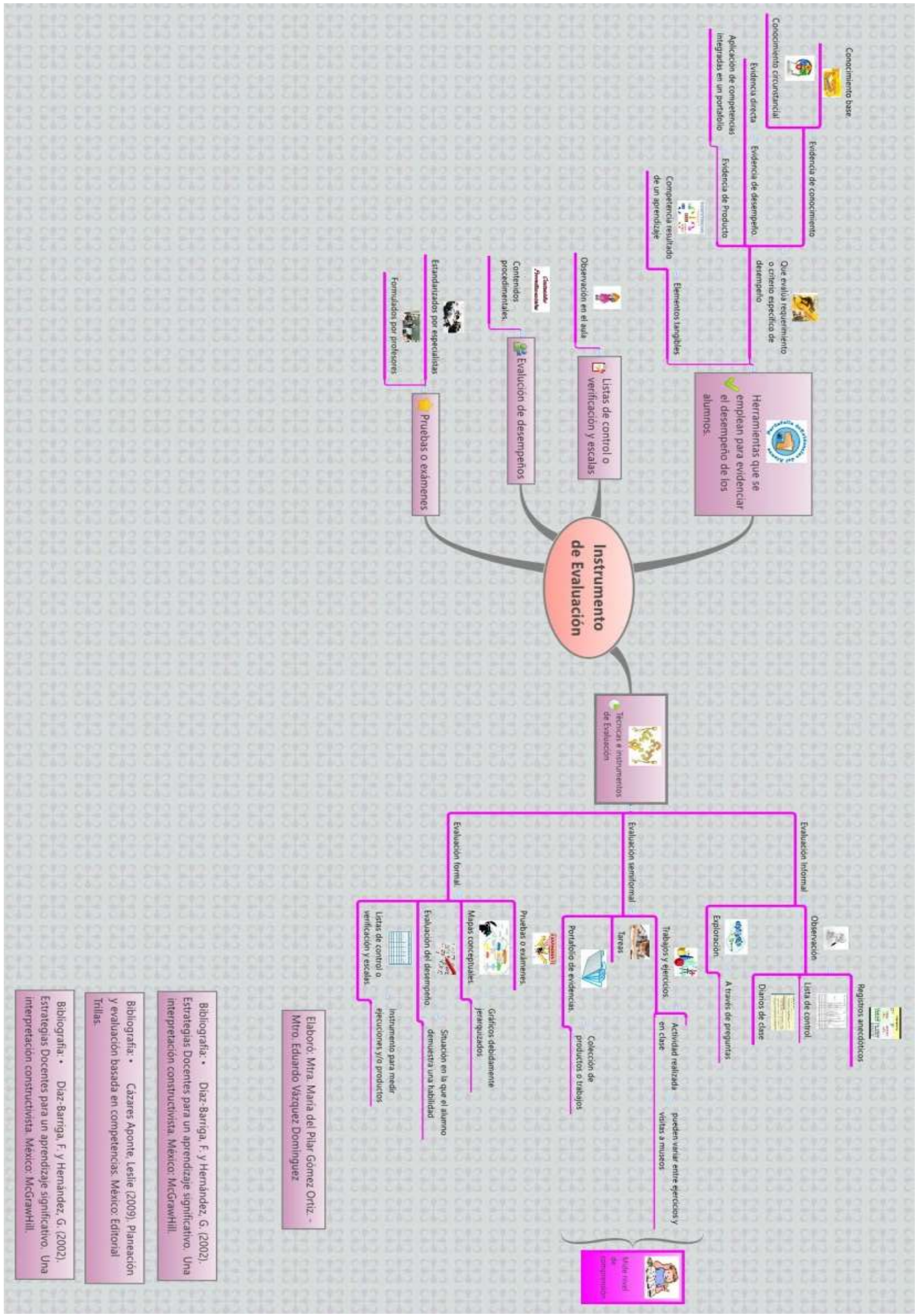




\section{Referencias}

[1] Cázares Aponte, Leslie (2009). Planeación y evaluación basada en competencias. México: Editorial Trillas.

[2] Díaz-Barriga, F. y Hernández, G. (2002). Estrategias Docentes para un aprendizaje significativo. Una interpretación constructivista. México: McGrawHill.
[3] Tejeda, F. J. La evaluación: su conceptualización. En Jiménez, B. (2000). Evaluación de programas, centros y profesores. Madrid: Síntesis Educación. Pag. 37. 